\title{
Best estimate of the magnitude of mortality due to occupational exposure to hazardous substances
}

\author{
Stephen Morrell, Charles Kerr, Tim Driscoll, Richard Taylor, Glenn Salkeld, \\ Stephen Corbett
}

Department of Public Health, University of Sydney, Australia

S Morrell

C Kerr

R Taylor

G Salkeld

Epidemiology Unit, National Institute of Occupational Health and Safety, Worksafe Australia, Sydney,

Australia

T Driscoll

Environmental Health Branch, New South

Wales Department of

Health, Australia

$S$ Corbett

Correspondence to: Dr T R Driscoll,

Epidemiology Unit, National Institute of Occupational

Health and Safety, Worksafe

Australia, GPO Box 58,

Sydney, NSW 2001,

Australia.

Accepted 31 March 1998

\begin{abstract}
Objectives-With a proportionate attributable risk approach, to estimate the magnitude of premature mortality induced by exposure to hazardous substances in the Australian workforce.

Methods-Estimates of the magnitude of mortality induced by exposure to hazardous substances in the Australian workforce were calculated by the proportionate attributable risk approach after careful consideration of options for methodological refinements. The main data sources used were unit mortality datasets (individual deidentified death records), and tabulations when these were unavailable.
\end{abstract}

Results-The estimated number of deaths that occurred in Australia each year from occupational exposure to hazardous substances was $2290 ; 78 \%$ of these were men. The rate of mortality attributable to occupational exposure to hazardous substances was three to four times greater in male workers than in female workers. Male (productive) person-years of life lost (PYLL) were generally eight times higher than female PYLL. Cancer was the prime cause of death, followed by renal, cardiovascular, neurological, and chronic respiratory disease. Acute toxic episodes accounted for a small proportion of mortality but yielded a much larger proportion of PYLL, reflecting the relatively young ages of those who experienced fatal effects.

Conclusions-Although national estimates of the proportions of mortality attributable to occupational exposure to hazardous substances seemed to be validly derived, uncertainties remain associated with the lack of an empirical basis for derivation of proportionate risk fractions used in the calculations. The finding of an appreciable burden of mortality that is attributable to past occupational exposure to hazardous substances emphasises the necessity for occupational health and safety authorities to measure and reduce worksite exposures. There is also an incentive to encourage the construction of appropriately designed cohort studies across industries and occupational groupings so that, ultimately, risk estimates may be directly calculated and applied to total workforce data for the definitive estimation of the magnitude of harm induced by occupational exposure to hazardous substances.

(Occup Environ Med 1998;55:634-641)

Keywords: mortality; hazardous substance; occupational

Available statistics such as workers' compensation suggest that musculoskeletal injury and dysfunction are the main occupational abnormalities in Australia. ${ }^{1}$ However, these data sources can be misleading because the more easily recognisable abnormalities - such as musculoskeletal disorders - are the ones which are more likely to be reported, recorded, acknowledged, and attributed to work through compensation. ${ }^{2}$

By contrast, abnormalities related to substances, although known to occur, are often hard to identify because the early effects can be subtle and the time between exposure and the development of symptoms can be substantial. Non-occupational exposures can also cause similar abnormalities to occupational exposures, so the establishment of true work relatedness can often be difficult.

Because of these problems in obtaining accurate and up to date information on the effect of occupational exposure to hazardous substances, the area has remained relatively neglected compared with acute workplace injuries and accidents. However, with the large number and volume of hazardous substances to which people may be exposed in Australian workplaces it is certainly possible that the effects on health of occupational exposure to hazardous substances are as important, or more important, than the health effects of occupational accidents and injuries.

To date, it has not proved possible to estimate directly the total magnitude of illness or premature mortality induced by hazardous substances in whole populations of workers, as opposed to specific industries or worksites. No investigators have succeeded in directly deriving the magnitude of harm associated with occupational exposure to hazardous substances in industrially advanced societies. Data from official sources, special collections, and risk estimation studies remain too incomplete for empirical investigations of magnitude in total worker populations. The quality of officially recorded information on disease outcomes and detailed workplace exposure has been too poor for direct estimation in populations that have been investigated in the United States, ${ }^{3}$ New York State, ${ }^{4}$ Israel, ${ }^{5}$ and New South Wales (NSW). ${ }^{6}$ Epidemiologically valid causal asso- 
ciations between exposure to hazardous substances and specified diseases are relatively few; and most hazardous substances available for industrial use either have unknown effects on exposed humans or incomplete, indirectly deduced, or inconsistent evidence of causing harm. Moreover, sound exposure data are difficult to obtain and progress in remedying the situation is predicted to be slow. For example, in 1985 the United States Office of Technology Assessment suggested that it would not be until well into the 21st century before the United States Occupational Safety and Health Administration (OSHA) had collected data from most of the worksites under its jurisdiction and then the data on chemical hazards would be incomplete because OSHA's emphasis is on physical safety and not on industrial hygiene sampling. ${ }^{7}$

Nevertheless, a case can be made for a significant body of harm originating from exposure to hazardous substances of workers despite extreme difficulties in constructing useful measures, which for some major outcomes - such as adverse effects on human reproduction-hardly exist. One of the few major studies in this area involved a year long investigation during 1986 in New York State which was designed to assess the nature and magnitude of occupational disease, and its costs, among a workforce of 7.7 million people. ${ }^{49}$ (An extension of this sort of approach to include injuries and to cover the whole of the United Stated has been recently published by the same author group. ${ }^{3}$ ) They lacked accurate identification of origins of mortality and morbidity data and were unable to aggregate data derived from risk estimations on specified worker subgroups, so they used the attributable risk approach to estimate the total number of deaths and morbidity rates in six disease categories (cancer, pneumoconiosis, chronic respiratory disease, cardiovascular disease, renal disease, and neurological disorders). Assumptions on the proportions of deaths attributable to occupationally hazardous substances were not clearly defined, but followed the Delphic principles used by Doll and Peto. ${ }^{10}$ Accordingly, uncertainties were introduced into the analyses and the New York investigators took a conservative approach to the attributable proportions. The conclusion was that $3 \%-4 \%$ of all deaths in the total population of New York State were attributable to work related exposures. It follows that this estimate may be accepted as an approximation of the percentage of deaths occurring in one particular relatively large population from adverse effects of use of industrial hazardous substances.

An indication that the proportion of $3 \%-4 \%$ of all deaths may be appropriate comes from other United States estimates. Minimal bounds of $1 \%-2 \%$ of all deaths are derived from the potentially fatal conditions on the NIOSH list of 50 sentinel occupational diseases that occur in industries where there are risks of relevant exposures to hazardous substances. ${ }^{11-13}$ Maximal bounds are reflected in the generally accepted estimates derived from different indirect approaches that $5 \%$ of all deaths in the
United States are due to diseases that are mainly occupational in origin - including those not caused by hazardous substances. ${ }^{14}$

The present study was planned on the assumption that there are considerable difficulties in obtaining accurate and up to date information on the health effects of occupational exposure to hazardous substances in Australia. A review of the literature on the magnitude of harm originating from exposure to industrial hazardous substances led to the conclusion that data are too incomplete for direct measurement and that the attributable proportion approach, despite considerable methodological difficulties, ${ }^{81015} 16$ remains the means by which approximations of magnitude can be derived. The aim of this study therefore was to estimate, with a proportionate attributable risk approach, the magnitude of premature mortality induced by exposure to hazardous substances in the Australian workforce.

\section{Methods}

This study considered deaths that were due to hazardous substances and which occurred in the four year period 1989-92 inclusive. National mortality information in aggregate form was obtained from the Australian Institute of Health and Welfare and was used for calculation of estimates of mortality and person-years of life lost (PYLL). Calculations of PYLL also used NSW unit record mortality information.

Hazardous substances were defined as any chemical substance that is used in, or is a product or byproduct of, an industrial process not known to be harmless. The term industrial is equated with occupational to qualify exposure of workers to hazardous substances. Excluded from direct consideration are domestic use or storage of hazardous substances, food additives, cosmetic use, the use of therapeutic substances, non-worksite exposure to waste chemical substances or environmental pollutants, and emissions from vehicles.

With some exceptions, general disease categories were defined according to the international classification of diseases revision 9 (ICD-9 $)^{17}$ with exclusion of the following hazardous substance entries: blasting materials (E923.0.1); hot water and steam (E924.0); legal intervention (E970-E977); assault (E961E962); chemical warfare (E997.2); and all categories of self inflicted poisoning (E950.0E952.9). The ICD-9 classifications for respirable dusts, mists, and vapours and for radioactive compounds (chemical effects only) were included under the definition of industrial hazardous substances.

National unit mortality data are held by the Australian Institute of Health and Welfare, whereas state unit mortality data are held by various bodies including state health departments and universities. State based data include age, sex, and occupation of the decedent. Both national and state data are derived from data held by the various state registries of Births, Deaths, and Marriages and digitised by the Australian Bureau of Statistics (ABS) to a uniform format. New South Wales unit mortality records and Australian Institute 
Table 1 Attributable fractions for those causes of death not directly produced by accidental poisoning in the workplace

\begin{tabular}{|c|c|c|}
\hline \multirow[b]{2}{*}{ Disease } & \multicolumn{2}{|c|}{$\begin{array}{l}\% \text { Attributable to } \\
\text { occupational exposure to } \\
\text { hazardous substances }\end{array}$} \\
\hline & Men & Women \\
\hline \multicolumn{3}{|l|}{ Non-cancer: } \\
\hline Cardiovascular disease & 1.0 & 1.0 \\
\hline Renal diseases & 1.0 & 1.0 \\
\hline Neurological diseases & 1.0 & 1.0 \\
\hline Chronic respiratory diseases & 1.0 & 1.0 \\
\hline Asthma & 2.0 & 2.0 \\
\hline Pneumoconiosis & 100.0 & 100.0 \\
\hline \multicolumn{3}{|l|}{ Cancer: } \\
\hline Cancer of mesentery and peritoneum & 15.0 & 5.0 \\
\hline Liver cancer & 4.0 & 1.0 \\
\hline Laryngeal cancer & 2.0 & 1.0 \\
\hline Lung cancer & 15.0 & 5.0 \\
\hline Cancer of pleura, nasal sinuses, and remaining respiratory sites & 25.0 & 5.0 \\
\hline Bone cancer & 4.0 & 1.0 \\
\hline Skin cancer (non-melanoma) & 10.0 & 2.0 \\
\hline Prostatic cancer & 1.0 & - \\
\hline Bladder cancer & 10.0 & 5.0 \\
\hline Leukaemia & 10.0 & 5.0 \\
\hline Other and unspecified cancers & 6.8 & 1.2 \\
\hline Cancer of mouth & 1.0 & 0.5 \\
\hline Cancer of oesophagus & 1.0 & 0.5 \\
\hline Stomach cancer & 1.0 & 0.5 \\
\hline Colorectal cancer & 1.0 & 0.5 \\
\hline Pancreatic cancer & 1.0 & 0.5 \\
\hline Connective tissue cancer & 1.0 & 0.5 \\
\hline Kidney cancer & 1.0 & 0.5 \\
\hline Cancer of brain & 1.0 & 0.5 \\
\hline Hodgkin's disease & 1.0 & 0.5 \\
\hline Non-Hodgkin's lymphoma & 1.0 & 0.5 \\
\hline
\end{tabular}

^Percentage assigned to diseases known to be caused by occupational exposure to hazardous substances $^{5810}$ which were used in this study.

of Health and Welfare mortality data for 1989-92 were analysed for specific E code chemically caused mortality, as well as other causes attributable to occupational exposure to hazardous substances.

Unit mortality data contain no information on the place of occurrence of an event. Estimates of mortality related to hazardous substance derived from this data set will tend to be slightly higher than the actual rates due to occupational exposure because a proportion of deaths from chemical poisoning occur in nonwork domestic situations.

With the exception of neoplasm of the pleura, proportions of mortality and morbidity due to occupational exposure to hazardous substances were used as established in the literature for major disease categories in countries of similar economic development to Australia. Such attributable proportions were used for this paper to estimate the mortality load due to occupational exposure to hazardous substances (table 1). Where these proportions were published as a range, the lower percentage was used. Where these ranges were derived with sex distinction, the lowest was used for women and the middle of the range proportion was used for men. Estimates presented in this paper therefore represent a conservative assessment of mortality attributable to occupational exposure to hazardous substances.

In the case of mesothelioma, attributable proportions were adjusted to reflect enhanced recording of information on disease held in specialist registries in Australia. Proportions assigned by Doll and Peto to neoplasm of the pleura attributable to occupational expoure to hazardous substances are $25 \%$ for men and $5 \%$ for women. Proportions assigned to neoplasm of the peritoneum are $15 \%$ for men and $5 \%$ for women. In Australia, the incidence of reporting of new cases of mesothelioma, and by implication mesothelioma mortality due to the disease's short survival time, is recorded in the annual reports of the Australian Mesothelioma Register. ${ }^{18}$ Published reports from this register do not contain mortality information. According to these reports, for the 1989-92 period there were about 250-300 new cases of mesothelioma reported annually across Australia, of which nearly $80 \%$ are estimated to be due to occupational exposure. ${ }^{19}$ Consequently, occupationally attributable proportions of neoplasms of the pleura and peritoneum assigned by Doll and Peto underestimate the number of mesothelioma cases by almost an order of magnitude. Even when $100 \%$ of all nationally recorded (death registry) male deaths from neoplasms of the peritoneum and pleura are ascribed to occupational asbestos exposure, the event numbers remain significantly less than those recorded by the Australian Mesothelioma Register. Estimates of the attributable proportions of neoplasms of the pleura and peritoneum were determined with adjusted cancer morphology data recorded by the NSW Central Cancer Registry. On the basis of these estimates, occupationally attributable proportions of mesothelioma from data sources of national deaths are taken to be $100 \%$ of malignant pleural and peritoneal neoplasms in men and $100 \%$ of malignant pleural neoplasms only in women.

Person-years of life lost were calculated for years of productive working life lost. This was applied to men who died at $<65$ years of age and to women who died at $<60$ years to reflect the retirement ages in Australia of men and women, respectively. Although retirement ages have been reduced in some work areas in the past few years, most of this has been confined to white collar occupations-for example, teachers, clerical staff, etc. Five-year age midpoints for each attributable disease for PYLL calculations were estimated by averaging ages (plus half a year to average out proximity of last birthday) at death for 1989-92, as derived from NSW unit mortality data. Single year age at death information is readily available from NSW unit mortality data but the Australian Institute of Health and Welfare is not permitted to release data in this format. Missing ages in causes of death with small numbers were substituted by the all cause average for the given five-year age bracket. Person-years of life lost were calculated taking into account competing causes of death and were age standardised to the 1991 Australian census population (appendix 1). The PYLL estimated would tend to be conservative and measures years of working life lost for each sex.

Results were calculated separately for each year and combined for the four years to produce an average annual rate. Only the combined results are presented here. Differences between each year varied by $<16 \%$. Although calculation of estimates involved separate con- 
Table 2 Estimated annual average number of deaths attributable to occupational exposure to hazardous substances by condition and sex, 1989-92, Australia

\begin{tabular}{|c|c|c|c|c|c|c|}
\hline \multirow[b]{2}{*}{ Cause of death } & \multicolumn{2}{|l|}{ Men } & \multicolumn{2}{|c|}{ Women } & \multicolumn{2}{|l|}{ Total } \\
\hline & $n$ & $\%$ & $n$ & $\%$ & $n$ & $\%$ \\
\hline Cancer & 1122 & 62.4 & 175 & 35.5 & 1297 & 56.6 \\
\hline Major diseases & 601 & 33.4 & 310 & 62.9 & 911 & 39.8 \\
\hline Dust diseases & 47 & 2.6 & 1 & 0.2 & 48 & 2.1 \\
\hline Acute chemical poisoning and injury & 27 & 1.5 & 7 & 1.4 & 34 & 1.5 \\
\hline Total & 1797 & 100.0 & 493 & 100.0 & 2290 & 100.0 \\
\hline
\end{tabular}

sideration of hundreds of conditions, the results presented aggregate the findings into five groups: cancers, major non-neoplastic diseases (comprising renal, chronic respiratory, cardiovascular, and neurological diseases), dust diseases, acute chemical poisoning, and injury, and all conditions combined.

Mortalities were directly age standardised with the estimated resident population for Australia of people $\geqslant 15$ years of age at the 1991 census. This allowed for estimating rates applicable to Australia from state limited data sources. Confidence limits for age standardised rate estimates were calculated based on a method derived by Dobson et $a l,{ }^{20}$ taking into account small numbers of events based on the Poisson distribution. Dobson's method was modified to allow for nominal fractional death numbers totalling $<1$ for valid $\chi^{2}$ significance estimates to be derived.

When mortality information was extrapolated from state data to Australia, 95\% confidence intervals ( $95 \%$ CIs) were calculated after multiplying the raw event numbers in each 5-year age bracket by the corresponding ratio of the Australian population to NSW population in each 5-year age bracket. Age standardised rates and 95\% CIs) were then calculated based on these weighted event numbers with the Australian population as the denominator. State projections of mortalities were compared with the national mortalities to assess the accuracy of the state rates.

\section{Results}

The estimated number of deaths that occur in Australia each year from occupational exposure to hazardous substances was 2920. Of these $78 \%$ were male (table 2 ). Similarly, the rate of mortality attributable to occupational exposure to hazardous substances was about five times greater in male workers than in female workers, with the mortality point estimate in men attributable to hazardous substances being 316 events per million per year for 1989-92, and the point estimate mortality in women being 63 events per million. The rate for people (men and women) was 172 events per million (table 3). Mean annual PYLL due to occupational exposure to hazardous substances was 5047 for men and 637 for women, making up a total estimate of 5683 PYLL (table 4).

\section{CANCER}

During $1989-92,57 \%$ of mortality attributable to hazardous substances was due to malignant neoplasms, with a point estimate of age standardised cancer mortality of 97 events per million. The corresponding rate for men was 191 events per million ( $61 \%$ of the male total) and for women it was 24 events per million (38\% of the female total).

Lung cancer accounted for the highest proportion of cancer mortality related to hazardous substances: $58 \%$ for all people ( 57 events per million), $60 \%$ for men (115 events per million) and $47 \%$ for women ( 11 events per million). Malignant mesothelioma accounted for $14 \%$ for all people ( 14 events per million), $14 \%$ for men ( 26 events per million), and $14 \%$ for women (three events per million). Male and female mortalities for malignant neoplasms of the peritoneum were similar, whereas the rate of malignant pleural neoplasms in men was between five and six times the rate in women.

Table 3 Estimated age adjusted mortality related to hazardous substance by condition and sex, 1989-92, Australia

\begin{tabular}{|c|c|c|c|c|c|c|c|c|c|}
\hline \multirow[b]{2}{*}{ Condition } & \multicolumn{3}{|l|}{ Men } & \multicolumn{3}{|l|}{ Women } & \multicolumn{3}{|l|}{ Total } \\
\hline & $\begin{array}{l}\text { Ratel } \\
\text { million/ } \\
\text { year }\end{array}$ & $(95 \% C I)$ & $\begin{array}{l}\% \text { Of total } \\
\text { mortality related } \\
\text { to hazardous } \\
\text { substances }\end{array}$ & $\begin{array}{l}\text { Ratel } \\
\text { million/ } \\
\text { year }\end{array}$ & $(95 \% C I)$ & $\begin{array}{l}\% \text { Of total } \\
\text { mortality related } \\
\text { to hazardous } \\
\text { substances }\end{array}$ & $\begin{array}{l}\text { Ratel } \\
\text { million/ } \\
\text { year }\end{array}$ & $(95 \% C I)$ & $\begin{array}{l}\% \text { Of total } \\
\text { mortality related } \\
\text { to hazardous } \\
\text { substances }\end{array}$ \\
\hline Cancer & 191 & (186 to 197 ) & 61 & 24 & (22 to 25$)$ & 38 & 97 & (94 to 100 ) & 57 \\
\hline Lung & 115 & (111 to 119 ) & 36 & 11 & (10 to 13 ) & 18 & 57 & (55 to 59$)$ & 33 \\
\hline Mesothelioma ${ }^{\star}$ & 26 & (24 to 29 ) & 8 & 3 & (3 to 4 ) & 5 & 14 & (13 to 15$)$ & 8 \\
\hline Leukaemia & 10 & (9 to 12 ) & 3 & 3 & ( 2 to 4$)$ & 5 & 6 & ( 6 to 7 ) & 4 \\
\hline Bladder & 9 & (8 to 10$)$ & 3 & 1 & (1 to 2 ) & 2 & 4 & (4 to 5 ) & 3 \\
\hline Major diseases & 112 & (107 to 117 ) & 36 & 38 & (36 to 40 ) & 60 & 68 & ( 66 to 71 ) & 40 \\
\hline Cardiovascular & 100 & (96 to 105 ) & 32 & 33 & (31 to 35 ) & 52 & 61 & (59 to 63 ) & 35 \\
\hline Asthma & 5 & (4 to 6 ) & 2 & 2 & (2 to 3 ) & 4 & 3 & (3 to 4 ) & 2 \\
\hline Dust diseases & 8 & (7 to 10$)$ & 3 & 0 & $(0$ to 0$)$ & 0 & 4 & (3 to 4 ) & 2 \\
\hline Asbestosis & 4 & (3 to 5 ) & 1 & 0 & $(0$ to 0$)$ & 0 & 2 & (1 to 2$)$ & 1 \\
\hline Silicosis & 3 & (2 to 4$)$ & 1 & 0 & $(0$ to 0$)$ & 0 & 1 & (1 to 2 ) & 1 \\
\hline $\begin{array}{l}\text { Acute chemical poisoning } \\
\text { and injury }\end{array}$ & 4 & (3 to 5 ) & 1 & 1 & (1 to 1 ) & 2 & 3 & (2 to 3 ) & 2 \\
\hline Total & 316 & (308 to 323 ) & 100.0 & 63 & (60 to 65 ) & 100.0 & 172 & (168 to 175$)$ & 100.0 \\
\hline
\end{tabular}

*These rate estimates include $100 \%$ attribution of malignant pleural and peritoneal neoplasms to occupational mesotheliomas in men and $100 \%$ of malignant pleural neoplasms in women. 
Table 4 Estimated annual age and cause adjusted productive years of life lost from mortality related to hazardous substances by condition and sex, 1989-92, Australia

\begin{tabular}{|c|c|c|c|c|c|c|}
\hline \multirow[b]{2}{*}{ Condition } & \multicolumn{2}{|l|}{ Men } & \multicolumn{2}{|l|}{ Women } & \multicolumn{2}{|l|}{ Total } \\
\hline & PYLL & Total \% & PYLL & Total \% & PYLL & Total \% \\
\hline Cancer & 3020.7 & 59.9 & 353.7 & 55.6 & 3374.4 & 59.4 \\
\hline Major diseases & 1294.9 & 25.7 & 209.3 & 32.9 & 1504.2 & 26.5 \\
\hline Dust diseases & 46.0 & 0.9 & 0.6 & 0.1 & 46.6 & 0.8 \\
\hline Acute chemical posioning and injury & 685.1 & 13.6 & 73.1 & 11.5 & 758.2 & 13.3 \\
\hline Total & 5046.7 & 100.0 & 636.7 & 100.0 & 5683.4 & 100.0 \\
\hline
\end{tabular}

PYLL=Productive years of life lost.

Leukaemia was the third highest cause of death from neoplasms attributable to hazardous substance in all people $(6 \%)$, followed by cancer of unspecified site $(5 \%)$, and bladder cancer $(5 \%)$. Corresponding percentages for men were leukaemia ( $5 \%$ ), cancer of unspecified site $(5 \%)$, and bladder cancer $(4 \%)$; and for women were leukaemia $(13 \%)$, cancer of unspecified site $(5 \%)$, and bladder cancer $(6 \%)$.

Estimated PYLL from malignant neoplasms attributable to hazardous substance are shown in table 4 . From cancer for all people PYLL was 3374 per year (3021 in men and 354 in women). Lung cancer was the single dominant neoplasm in men, making up $52 \%$ of PYLL from cancer in men, followed by leukaemia $(12 \%)$, malignant mesothelioma (11\%), neoplasms from non-specified sites (6\%), and non-melanoma skin cancer (4\%). For women, lung cancer attributable to occupational exposure to hazardous substances also accounted for the highest proportion of PYLL due to cancer $(33 \%)$, followed by leukaemia (26\%), mesothelioma (18\%), and neoplasms from non-specified sites ( $5 \%)$.

MAJOR NON-NEOPLASM DISEASES

Proportions of total mortality related to hazardous substances accounted for by major non-neoplasm disease categories during 1989-92 were $40 \%$ for all people (68 events per million), $36 \%$ for men (112 events per million), and $60 \%$ for women (38 events per million) (table 3). Cardiovascular disease mortality made up $88 \%$ of all total mortality in this category (61 events per million), with similar percentages for men and women. Asthma accounted for $5 \%$ of major disease mortality in all people, again with similar percentages in men and women.

Major non-neoplasm diseases related to hazardous substances made up $27 \%$ of all total, $26 \%$ of male, and $33 \%$ of female PYLL, accounting for 1504, 1295, and 209 PYLL

Table 5 Ranges for estimates of total number of deaths from occupational exposure to hazardous substances using different attribution rates for cardiovascular disease and lung cancer, 1989-92, Australia

\begin{tabular}{lcll}
\hline Attribution rate (\%) & $\begin{array}{l}\text { Deaths from cardiovascular } \\
\text { disease or lung cancer }\end{array}$ & $\begin{array}{l}\text { All other cause } \\
\text { deaths }\end{array}$ & Total deaths \\
\hline Cardiovascular: & & & \\
0 & 0 & 1481 & 1481 \\
1 & 808 & 1481 & 2289 \\
3 & 2424 & 1481 & 3905 \\
Lung cancer: & 507 & 1528 & 2035 \\
10 & 761 & 1528 & 2289 \\
15 & 1015 & 1528 & 2543 \\
20 & & & \\
\hline
\end{tabular}

^Number of deaths from all other causes as estimated for the main study results. respectively (table 4). Cardiovascular disease made up $75 \%$ of the major non-neoplastic diseases that caused PYLL in men and $50 \%$ in women. Mortality from asthma attributable to hazardous substance was the second highest contributor to PYLL from major nonneoplastic disease, making up $15 \%$ in men and $34 \%$ in women. Neurological diseases attributable to hazardous substances ranked third among the major non-neoplastic diseases, with $8 \%$ of PYLL in men and $11 \%$ in women.

\section{DUST DISEASES}

Mortality from dust diseases comprised $2 \%$ of the total mortality from hazardous substances (four events per million), with corresponding figues for men being 3\% (eight events per million) and for women being $0 \%(<0.1$ event per million) (table 3). Asbestosis (two events per million in all people, four events per million in men) and silica pneumoconiosis (one event per million in all people, three events per million in men) accounted for the largest proportions of mortality from dust diseases. Estimated PYLL due to mortality from dust diseases were 47 a year for all people (nearly all due to male deaths), about $1 \%$ of total PYLL attributable to hazardous substances (table 4).

MORTALITY FROM ACUTE CHEMICAL POISONING AND INJURY

During the study period acute chemical poisoning was estimated to have comprised between $1 \%$ and $2 \%$ of total, male, and female mortality related to hazardous substances (three events, four events, and one event per million, respectively, table 3). Mortality from gases made up the largest proportion of chemical poisoning, accounting for $33 \%$ of total deaths from chemical poisoning (men $38 \%$, women $12 \%$ ). Productive years of life lost due to acute chemical poisoning were estimated to be 758 for all people (685 for men; 73 for women), with proportions being $13 \%$ for all people, $14 \%$ for men, and $11 \%$ for women (table 4).

\section{Discussion}

The estimated number of deaths that occur in Australia each year from occupational exposure to hazardous substances was 2290. Mortality attributable to occupational exposure to hazardous substances was three to four times greater for men than for women. Cancer was the main category of mortality for both sexes, then chronic non-malignant conditions (renal, cardiovascular, neurological, and chronic respiratory disease). Acute poisoning 
accounted for a small proportion of deaths, but contributed a relatively much larger proportion to total PYLL, reflecting the young age of those afflicted.

These estimates of the number and rates of deaths resulting from occupational exposure to hazardous substances can be compared with other causes of death which have a high profile in the community. For example, in Australia in 1992 there were 2066 road deaths (120 per million people), 2294 deaths from suicide (130 per million people), and 643 deaths related to AIDS (36 per million people). ${ }^{21}$ For $1982-4$, which is the most recent period for which there is comprehensive Australian national information available, there were 515 traumatic work related fatalities ( 81 per million people). ${ }^{22}$ Comparable findings from this study are 2239 deaths at a rate of 161 per million people $\geqslant 15$ years of age. Although these data are not standardised for age, whereas those calculated for this study are, and they cover different time intervals, it is clear that current mortality due to occupational exposure to hazardous substances in the workplace is an important public health problem in Australia.

The implications for current occupational health and safety practice are not straightforward but the findings are cause for concern. Relevant exposures are likely to have occurred many years previously and the type and extent of many of these exposures have improved. Deaths that follow soon after acute exposures (primarily poisonings) are an exception. Conversely, the effect of current occupational exposures to hazardous substances in the workplace is not considered by these findings, other than for poisonings. There may be exposures occurring now that will lead to ill health in the future, either because the level of exposure is underestimated (or unknown) or the risk posed by certain exposures (singly or in combination) is not properly recognised. However, because of the long latency period the health effects of current exposures will probably not be evident for several years. What these findings do indicate is that past exposures have resulted in considerable mortality and that some current acute exposures are causing problems currently. They also imply that the effects of current exposures need to be carefully considered, because the potential health effects may be important but not evident for many years. Also, the data presented here represent aggregate results for the whole workforce. Within this workforce there are likely to be smaller groups who face much higher risks of developing fatal work related disorders as a result of exposure to hazardous substances than does the total population.

\section{METHODOLOGICAL CONSTRAINTS ON THE} FINDINGS

In this investigation, widely used attributable risk fractions for diseases induced by hazardous substances were applied to routinely collected aggregate data to estimate the magnitude of disease in the Australian population resulting from occupational exposure to hazardous substances. These data were supplemented by some limited direct information on acute exposure to hazardous substances and more extended national information on mesothelioma attributable to occupational exposure to asbestos. Whereas the aggregate data that were used and the analytical methods may be considered reasonably valid, the attribution of particular fractions of disease depends on assumptions which do not possess a firm empirical basis. Accordingly, all conclusions on resulting estimates must remain guarded.

The validity of the attributable proportions which have been assigned to these major disease categories is debatable. Doll and Peto, ${ }^{10}$ for example, justify their occupationally attributable proportions of cancers by resort to panels of experts-the so called Delphic technique. Further, when some cancers were thought to be probable results of occupational exposure to hazardous substances, arbitrary proportions were assigned to these. Markowitz et $a l^{\beta}$ provide little justification for attributable proportions arrived at for cardiovascular, respiratory, neurological, and renal diseases. Although these proportions are stated for occupational diseases, and not specifically from exposure to hazardous substances in the workplace, there are few established biological pathways for these diseases in the occupational setting which are not associated with exposure to a hazardous substance. For instance, the putative positive relation between stress at work and hypertension is not well supported in published literature. ${ }^{23}$ None the less, the results in the current report, especially for the more common disease categories, are not underpinned by strong attribution methods.

The main uncertainties in the overall estimates of deaths a year from occupational exposure to hazardous substances arise from the attributable fractions used for cardiovascular disease $(1 \%)$ and lung cancer $(15 \%)$. As both these groups of diseases are common causes of mortality in the general community, even a small attribution rate can result in an important contribution to the total number of fatalities. The attribution rate for cardiovascular disease due to chemical exposure is particularly likely to cause comment, with an attribution rate close to zero being accepted by many people, whereas others accept an attribution rate $>1 \% .^{24} 25$

There is no simple way to deal with this problem. The attribution rates are only estimates, but they remain the best estimates currently available. One approach that gives an indication of the range in which the true number of total deaths related to occupational exposure to hazardous substances probably lies is to provide estimates including a likely lowest and likely highest attribution rate. The results of this approach are shown in table 5 . With a range of attribution rates for cardiovascular disease of $0 \%-3 \%$ the estimated total number of deaths varied from $65 \%-171 \%$ of the main study estimate. Similarly, with extreme attribution rates for lung cancer of $10 \%$ and $20 \%$ the estimated total number of deaths varied from $89 \%-111 \%$ of the main study estimate. 
It should be stressed that the purpose of this paper is not to derive new estimates for attributable proportions, more suited to conditions in Australia, of common causes of death due to occupational exposure to hazardous substances. In most industries in Australia there is simply insufficient exposure data and expertise to confirm or deny estimates already arrived at elsewhere by, for example, Doll and Peto. With lack of evidence to the contrary, especially from Australia, attributable proportion estimates from countries such as the United States and elsewhere have been heavily relied on. ${ }^{810}$ Malignant mesothelioma is an exception to this approach.

Mortality estimates of occupational exposure to hazardous substances are dominated by conditions only indirectly attributable to occupational exposure to hazardous substances: malignant neoplasms and major disease categories - such as cardiovascular, respiratory, and renal diseases. Acute chemical poisoning contributes $2 \%$ of all mortalities related to hazardous substances. The contributions made by attributable proportions of the major disease categories to mortality and morbidity related to hazardous substances may be regarded as measures of the health load due to chronic long term occupational exposure to, or long disease latencies resulting from, past exposure to hazardous substances, as noted earlier.

Inferring mortalities due to acute occupational exposure to hazardous substances from routinely collected mortality data is prone to overestimation because the place of occurrence of exposure is not stated on death certificates. Mortalities from domestic and utility gases especially, would tend to be an overestimate because some of these deaths would have occurred at home. Death from petrol fumes is another category which is a probable overestimate, due to young people dying from sniffing petrol. Some adjustment for this was attempted by excluding some deaths on the basis of the cause, age, and occupation recorded in the deaths data, but only from the NSW unit mortality records. As most work related deaths from acute poisoning are likely to have been reported to the coroner, and his information for 1989-92 would have been the best source of data to identify these deaths for this study. However, this information was not available when the present study was conducted. Results of a study of work related traumatic deaths in Australia from an earlier period (1982-4) by Harrison et $a l,{ }^{22}$ which used coroner's data, suggest that the estimates of acute work related poisoning and associated PYLL in the current study are too high by a factor of three. However, as acute poisonings only made up about $2 \%$ of the total mortality estimates in the study (and 13\% of total PYLL), the effect of any error from this source would be small. Small numbers of events occurring across a variety of acute chemical poisoning types do not provide consistent year to year patterns of mortality from acute chemical exposure, but it seems that utility gases and carbon monoxide poisoning often account for a large proportion of mortality from chemical poisoning: $40 \%-$
$70 \%$ for men (three to four events per million) and $50 \%-60 \%$ for women ( 0.4 to one events per million).

Difficulties encountered with deriving estimates by the attributable risk approach suggest that definitive estimates of disease induced by occupational exposure to hazardous substances will not be achieved until workers in relevant industries are integrated into appropriately conducted prospective cohorts designed to relate exposures directly to effects. One approach to improving attributable proportion estimates could be to derive these empirically from health and mortality data reflecting more accurately the mix of industries and occupations in Australia. An obvious and simple prerequisite for this would be the addition of two fields to routinely collected health data: occupation and industry of the person. Addition of a variable in the national deaths data set which identified place of occurrence (as included in ICD-10) for external cause of death would also be very useful for appropriately identifying work related acute events. Plainly, these can give no quantitative indication of exposure to hazardous substances. However, as long as corresponding population denominators are routinely accessible, then ranges of attributable proportions could be estimated by developing models based on regression techniques outlined by, for example, Norstrom ${ }^{26}$ for deriving relative risks from aggregate data. Improved estimates of prevalences of confounders such as smoking for use in such analyses could be derived from the national health survey, which is also stratified by occupation and industry. ${ }^{27}$ If the sample size of the national health survey was increased to enable reliable estimation of prevalence of smoking and other confounders by occupation and industry at least to the two digit level, then it should in principle be possible to derive more accurate attributable proportions of mortality and morbidity for estimating occupational exposure to hazardous substances. This would represent a qualitative advance on estimates of attributable proportions put forward by the sources used for the present study.

A more active approach is the development of surveillance networks for conditions of importance which would provide efficient, timely, and ongoing assessment of their extent and allow appropriate early response to changes in their incidence and severity. As there are no such networks currently operating in Australia, initially there would need to be options developed for sentinel surveillance with particular emphasis on continuing operational frameworks and developing pilot projects. A national occupational health and safety surveillance system would evolve from such a strategy. Important components of this strategy include physician reporting, use of direct surveys, exposure surveillance, use of existing data sources, building surveillance networks, and evaluation. There should also be regular publishing of information and commentaries on, and evaluation of, national occupational health and safety surveillance systems. The National Occupational Health and Safety 
Commission is currently in the early stages of establishing such a strategy. ${ }^{28}$

\section{Conclusions}

The finding in the present study of appreciable burdens of mortality that are attributable to occupational exposure to hazardous substances emphasises the necessity for occupational health and safety authorities to monitor and reduce worksite exposures. There is also an incentive to encourage the construction of appropriately designed cohort studies across industries and occupational groupings so that, ultimately, risk estimates may be directly calculated and applied to total workforce data for the definitive estimation of the magnitude of harm induced by exposure to occupational hazardous substances.

This paper is the result of a project funded by a Development Grant from Worksafe Australia and is based on the epidemiological component of the funded project. The opinions expressed in this paper are those of the authors and not necessarily those of their employers.

\section{Appendix: Calculation of person-years of life lost (PYLL)}

PYLL was calculated taking into account competing causes of death, and was age standardised to the 1991 Australian census population, with the following formulae:

(1) Person-years of life lost taking into account competing causes of death:

$$
\equiv \mathrm{PYLL}_{\mathrm{cc}}=\sum_{\mathrm{i}=1}^{\mathrm{n}}\left[\mathrm{D}_{\mathrm{ik}} \star \mathrm{P}_{\mathrm{i}-\mathrm{k}} \star\left(\mathrm{T}-\mathrm{A}_{\mathrm{ik}}\right)\right]
$$

where, $D_{i \mathrm{k}}=$ No of deaths from cause $\mathrm{k}$ in the ith age group

$\mathrm{A}_{\mathrm{ik}}=$ average age in ith age bracket in which deaths from cause $\mathrm{k}$ occur

$\mathrm{T}=$ Terminal age $(65$ for men, 60 for women)

and $\mathrm{P}_{\mathrm{i}-\mathrm{k}}=\left\{\begin{array}{l}\prod_{\mathrm{x}=\mathrm{i}+1}^{\mathrm{n}-1}\left[1-\left(\mathrm{D}_{\mathrm{x}}-\mathrm{D}_{\mathrm{xk}}\right) / \mathrm{P}_{\mathrm{x}}\right], \mathrm{x}<\mathrm{n} \\ 1, \mathrm{x}=\mathrm{n}\end{array}\right.$

$\mathrm{D}_{\mathrm{x}}\left(\equiv \mathrm{D}_{\mathrm{i}}\right)=$ All deaths in ith age group

$\mathrm{P}_{\mathrm{x}}\left(\equiv \mathrm{P}_{\mathrm{i}}\right)=$ Denominator population in ith age group

(2) Person-years of life lost taking into account competing causes, age standardised:

$$
\equiv \mathrm{PYLL}_{\mathrm{ascc}}=\sum_{\mathrm{i}=1}^{\mathrm{n}}\left[\mathrm{D}_{\mathrm{ik}} \star \mathrm{P}_{\mathrm{i}-\mathrm{k}} \star\left(\mathrm{T}-\mathrm{A}_{\mathrm{ik}}\right)^{\star} \mathrm{Q}_{\mathrm{si}} / \mathrm{Q}_{\mathrm{i}}\right]
$$

where, $\mathrm{Q}_{\mathrm{si}}=\mathrm{P}_{\mathrm{si}} / \mathrm{P}_{\mathrm{s}}$ and $\mathrm{Q}_{\mathrm{i}}=\mathrm{P}_{\mathrm{i}} / \mathrm{P}$, and

where, $\mathrm{P}_{\mathrm{si}}=$ standard population in ith age group

$\mathrm{P}_{\mathrm{s}}=$ total standard population

$\mathrm{P}_{\mathrm{i}}^{\mathrm{s}}=$ denominator population in ith age group

$$
\mathrm{P}=\text { total denominator population }
$$

1 Foley G, Fung A, Davis M, et al. Compendium of workers compensation statistics, Australia, 1994-5. Canberra: Australian Government Publishing Service, 1996.

2 Driscoll TR. Are work-related injuries more prevalent than disease in the workplace? Occup Med 1993;43:164-6.

3 Leigh JP, Markowitz SB, Fahs M, et al. Occupational injury and illness in the United States. Estimates of costs, morbidity and mortality. Arch Intern Med 1997;157:1557-

4 Landrigan PJ, Markowitz S. Current magnitudes of occupational disease in the United States. Ann NY Acad Sci 1989; 57:27-45.

5 Blanc PD, Becker CE. Occupational health planning in Israel: a US perspective. Isr f Med Sci 1992;28:500-8.

6 Corbett S, Corvalan C, Gutteridge J, et al. The magnitude of health disorders resulting from exposure to industrial chemicals. Sydney: WorkCover Authority, 1990

7 US Office Of Technology Assessment. Priority illness and injury in the workplace. Washington, DC: US Congress, 1985. (OTA-H-256.)

8 Markowitz SB, Fischer E, Fahs MC. Occupational disease in New York state: a comprehensive examination. Am f Ind Med 1989;16:417-35.

9 Fahs MC, Markowitz SB, Fischer E, et al. Health costs of occupational disease in New York state. Am f Ind Med 1989;16:437-49.

10 Doll R, Peto R. The causes of cancer: quantitative estimates of avoidable risks of cancer in the United States today. $\mathcal{f}$ Natl Cancer Inst 1981;66:1196-308.

11 Rutstein DD, Mullan RJ, Frazier TM. Sentinel health events (occupational): a basis for physician recognition and public health surveillance. Am F Public Health 1983;73:1054-62.

12 Lalich NR, Schuster LL. An application of the sentinel health event (occupational) concept to death certificates. Am F Public Health 1987;77:1310-4.

13 Feldman JP, Gerber LM. Sentinel health event (occupational): analysis of death certificates among residents of Nassau County, NY, between 1980-2 for occupationally related causes of death. Am $\mathcal{F}$ Public Health 1990;80:158-61.

14 Markowitz SB. The role of surveillance in occupational health. In: ROM WN, ed. Environmental and occupational medicine, 2nd ed. Boston: Little Brown, 1992:19-28.

15 Chan-Yeung M, Lam S. Occuptional asthma. Am Rev Respir Dis 1986;133:686-703.

16 Steineck G, Plato N, Norell E. Urothelial cancer and some industry-related chemicals: an evaluation of the epidemiologic literature. Am f Ind Med 1990;17:371-91.

17 World Health Organisation. Manual of the international classification of diseases and causes of death, 9th revision, 2 volumes. Geneva: WHO, 1977.

18 Leigh J, Driscoll T, Baker G, et al. The Australian mesothelioma program: recent research results. fournal of Occupational Health and Safety-Australia New Zealand 1991;7: 365-71.

19 Leigh J, Hull B, Davidson P. The incidence of mesothelioma in Australia 1992 to 1994. Australian Mesothelioma Register Report, 1996. National Institute Report. Canberra: Australian Government Printing Service, 1996

20 Dobson AJ, Kuulasmaa K, Eberle E, et al. Confidence intervals for weighted sums of Poisson parameters. Stat Med 1991;10:457-62.

21 Castles I. Deaths, Australia 1992. Canberra: Australian Bureau of Statistics, 1993. (3302.0.)

22 Harrison JE, Frommer MS, Ruck EA, et al. Death as a result of work-related injury in Australia, 1982-4. Med 7 Aust 1989;150:118-25

23 Winkleby MA, Ragland DR, Syme SL. Self-reported stressors and hypertension: evidence of an inverse association. Am F Epidemiol 1988;127:124-34.

24 Kraut A. Estimates of the extent of morbidity and mortality due to occupational diseases in Canada. Am $\mathcal{F}$ Ind Med 1994;25:267-78

25 Olsen O, Kristensen TS. Impact of work environment on cardiovascular diseases in Denmark. F Epidemiol Community Health 1991;45:4-10.

26 Norstrom T. Deriving relative risks from aggregate data-1. Theory. F Epidemiol Community Health 1988;42:333-5

27 Castles I. 1989-90 National health survey:summary of results, Australia. Canberra: Australian Bureau of Statistics, 1991. (4364.0.)

28 Macaskill P, Mandryk J, Leigh J. Improved coverage and relevance of national occupational health and safety surveillance in Australia. National Institute Report. Canberra: Australian Government Publishing Service, 1995. 